\title{
Prevention of medical malpractice and disputes through analysis of lawsuits related to coronary angiography and intervention
}

\author{
Cheol Won Hyeon ${ }^{1}$, Won Lee ${ }^{2,3},{ }^{*}$, So Yoon Kim ${ }^{2,3}$, Ji Yong Park ${ }^{4}$, and Su Hwan Shin ${ }^{5,6}$
}

\begin{abstract}
${ }^{1}$ Division of Cardiology, Department of Medicine, Samsung Medical Center, Sungkyunkwan University School of Medicine, Seoul; ${ }^{2}$ Division of Medical Law and Bioethics, Department of Medical Humanities and Social Sciences, Yonsei University College of Medicine, Seoul; ${ }^{3}$ Asian Institute for Bioethics and Health Law, Yonsei University, Seoul; ${ }^{4}$ Yonsei University Law School, Seoul; ${ }^{5}$ Doctoral Program in Medical Law and Ethics, Yonsei University, Seoul; ${ }^{6}$ Blue Urology Clinic, Seoul, Korea
\end{abstract}

Received: October 13, 2018 Revised : December 3, 2018 Accepted: January 7, 2019

\section{Correspondence to}

Su Hwan Shin, M.D.

Blue Urology Clinic, 99

Sinchon-ro, Seodaemun-gu,

Seoul 03779, Korea

Tel: +82-2-365-5671

Fax: +82-2-365-5673

E-mail:jm5802@hanmail.net

*Current affiliation:

Department of Nursing, Chung-

Ang University, Seoul, Korea
Background/Aims: Possible fatal complications arising from coronary angiography (CAG), percutaneous coronary intervention (PCI), and coronary artery disease itself, are likely to cause medical disputes. Presenting the current status and reasons for judgments given in lawsuits related to CAG/PCI, this study aimed to identify ways to prevent unnecessary disputes and medical malpractice suits related to CAG/PCI through lawsuit analysis.

Methods: A total of 13 cases (20 judgments) found in the Supreme Court of Korea's Written Judgment Management System from 1998 to 2017 were analyzed.

Results: Coronary artery injury was the most common causative complication that led to lawsuits $(n=6,46 \%)$. Six cases $(46 \%)$ were ruled in favor of the plaintiff for violation of duty of care $(n=4)$ and duty of explanation $(n=2)$, respectively. Cases that violated duty of care included two errors in intra-procedure device manipulation, one in pre-procedure diagnosis, and one in management of post-procedure complication. Lack of explanation regarding the risk of complications was pointed out in both cases that violated duty of explanation. The average awarded amount for the damages was 114,436,064 Korean won.

Conclusions: Physicians need not fear unfair judgments so long as they follow standard of care because the Court consistently looked at the probability, the foreseeability, and the evidence. Therefore, maintaining standard of care is important. Besides, specific, detailed, and comprehensible explanations, including the risk of complications in addition to the necessity of procedures, are important to ensure the patient clearly understands the possible risk of adverse outcomes.

Keywords: Coronary angiography; Percutaneous coronary intervention; Malpractice; Dissent and disputes; Jurisprudence

\section{INTRODUCTION}

With the right to self-determination becoming important in recent times, patients are asked to actively participate in the decision-making process for treatment. Although advancements in information and communication technology has led to a greater dissemination of medical information easier, insufficient doctor-patient communication and a negative view of the public regarding the authority of doctors have created a feeling of distrust toward doctors. Hence, many medical accidents are attributed to doctor negligence (action or lack of action during a medical procedure that leads to illness, disability, or death) by the general population and 
lead to medical disputes [1,2].

Coronary artery disease is one of the leading causes of death worldwide [3-5]. Since decades of medical advancement, coronary angiography (CAG) and percutaneous coronary intervention (PCI) have remained the mainstay treatments for coronary artery disease. As the complexity of the procedure increases to include broader indications of chronic total occlusion, calcified coronary disease, and cardiogenic shock [6], the likelihood of complications related to the procedure may increase despite the contribution of the procedures to better prognosis.

In Korea, more than 50,000 patients receive PCI annually. The number of patients increased by $8 \%$ during the period 2011 to 2015 and shows a steadily increasing trend. Correspondingly, with 178 centers in 2015 , there was an increase of $17 \%$ in the number of centers capable of performing PCI from 2011 [7]. Since medical disputes related to CAG and PCI may well increase in the future, interventional cardiologists may not be able to completely avoid medical disputes during their careers.

However, there has been no previous research on actual disputes related to CAG/PCI in Korea. In this paper, the current status in relation to such disputes is presented, and the reasons for admitted or dismissed faults was analyzed with actual lawsuits. Furthermore, we tried to identify ways to prevent unnecessary disputes and medical malpractice suits.

\section{METHODS}

Judgments were collected from the databases of the Supreme Court of Korea's Written Judgment Management System and each court's service, which provides copies of the judgment to any subscriber [8]. Malpractice lawsuits involving CAG/PCI were included in this study, based on judgments entered from January 1998 to December 2017. A total of 78 lawsuit judgments were obtained with the search terms "coronary angiography," "coronary stent," "percutaneous coronary intervention," and "compensatory damage in medical practice." Duplicate cases, or those where CAG/PCI was only mentioned (but not a main issue of the lawsuit) were excluded. In total, 13 cases with 20 judgments were classified as judgments related to medical accidents in which CAG and intervention were disputed procedures.

From the descriptions of the judgments, information on the age, sex, type of defendant institution, claimed amounts, disputed complications, and severity of injury were collected. Direct mention of the diagnosis was also given in some reports. Based on the presence of ST-segment elevation or the disease course mentioned (such as exertional or resting chest pain), the diagnoses were classified into stable angina, unstable angina, non-STsegment elevation myocardial infarction (NSTEMI), and ST-segment elevation myocardial infarction (STEMI). If there was no specific evidence of disease classification on the judgments, they were mentioned as unclassifiable angina or myocardial infarction (MI).

Information about lawsuit case number, year of the final judgment, and court process (from First instance to Appeal to Supreme Court in the three-level court system) was collected. Cases were classified based on whether the plaintiffs (who filed a formal complaint with the court) won or lost. In cases that ruled in favor of the plaintiff, details regarding the awarded (to give a judgment of money to a party to a lawsuit claim) damages-consolation money (compensation for mental suffering caused by an illegal act), limitation of liability (a ruling that reduces someone's legal responsibility for damages by \%), lost earning capacity (a decrease in a person's ability to earn income), expense of funeral, and expense of treatment-in Korean won (KRW) were collected and analyzed.

In light of the fact that the physician's legal obligations are mainly concerned with duty of care (legal obligation to take reasonable care to avoid causing damage) and duty of explanation (legal obligation to explain procedure from civil law), the reasons for plaintiffs' claims, indemnities (security or protection against a loss or damage), or dismissals for each duty were separately collected and analyzed. Reasons for each indemnity or dismissal were reviewed to learn from the results.

The content of each judgment was analyzed independently by a cardiologist (C.W.H.) and a physician for medical law and ethics (S.H.S.). In the case of a conflict between the two authors, a review by a doctor of public health (W.L.) was conducted.

The study was conducted on the basis of a judgment published publicly in the database of Korean Supreme Court Judgment System. The courts have completed an- 
onymization in advance, making access to sensitive personal information impossible. Therefore, Institutional Review Board (IRB) approval was not required.

\section{RESULTS}

\section{General characteristics}

The general characteristics of the cases involved in this study are presented in Table 1 . Among 13 patients, seven $(54 \%)$ were male. The sex of six patients $(46 \%)$ was not identified. The number of patients aged below 60 was three (23\%), and above 60 was four (31\%). The age of the other six patients (46\%) was not identified. Regarding the type of defendant institution, six cases (46\%) were from general hospitals and seven cases (54\%) were from tertiary hospitals. According to the diagnoses, six patients $(46 \%)$ had angina pectoris.

Among the patients with angina pectoris, three (23\%) had stable angina, two (15\%) had unstable angina, and one (8\%) had unclassifiable angina. Seven patients had MI (54\%). Among the patients with MI, two (15\%) had NSTEMI, three (23\%) had STEMI, and two had unclassifiable MI.

The most common complication that caused the disputes was coronary artery injury with six cases (46\%), including three cases $(23 \%)$ of coronary perforation, two cases $(15 \%)$ of coronary dissection, and one case (8\%) of iatrogenic atheroma rupture. In relation to device failure, there was one case (8\%) of stent thrombosis and one case (8\%) of residual stent balloon after deflation failure. Disease-related complications included atrioventricular (AV) block, myocardial rupture, and suspected ventricular fibrillation or spasm, with one case each.

The complications resulted in the death of 11 patients (85\%), one patient had hypoxic brain damage, and another patient had to undergo follow-up out-patient department care due to ischemic heart failure. A detailed summary of all the cases is listed in Table 2.

\section{Trial outcome}

Of the total 13 cases, seven (54\%) were dismissed and the other six (46\%) were ruled in favor of the plaintiffs. Of the six awarded cases, four (31\%) were recognized as violation of duty of care and the other two (16\%) were recognized as violation of duty of explanation (Fig. 1A).
Table 1. General characteristics of cases $(n=13)$

\begin{tabular}{|c|c|}
\hline Characteristic & Number \\
\hline \multicolumn{2}{|l|}{ Sex } \\
\hline Male & 7 \\
\hline Female & o \\
\hline Not identified & 6 \\
\hline \multicolumn{2}{|l|}{ Age, yr } \\
\hline$\leq 60$ & 3 \\
\hline$>60$ & 4 \\
\hline Not identified & 6 \\
\hline \multicolumn{2}{|l|}{ Type of defendant institution } \\
\hline General hospital & 6 \\
\hline Tertiary hospital & 7 \\
\hline \multicolumn{2}{|l|}{ Diagnosis } \\
\hline Angina pectoris & 6 \\
\hline Stable angina & 3 \\
\hline Unstable angina & 2 \\
\hline Unclassifiable & 1 \\
\hline Myocardial infarction & 7 \\
\hline NSTEMI & 2 \\
\hline STEMI & 3 \\
\hline Unclassifiable & 2 \\
\hline \multicolumn{2}{|l|}{ Causative complication } \\
\hline Coronary artery injury & 6 \\
\hline Perforation & 3 \\
\hline Dissection & 2 \\
\hline Iatrogenic atheroma rupture & 1 \\
\hline Device failure & 2 \\
\hline Stent thrombosis & 1 \\
\hline $\begin{array}{l}\text { Residue of stent balloon after deflation } \\
\text { failure }\end{array}$ & 1 \\
\hline Disease-related complications & 3 \\
\hline AV block & 1 \\
\hline Myocardial rupture & 1 \\
\hline Ventricular fibrillation or spasm & 1 \\
\hline Miscellaneous complications & 2 \\
\hline Hemothorax & 1 \\
\hline Ruptured aortic dissection & 1 \\
\hline \multicolumn{2}{|l|}{ Grave injury } \\
\hline Death & 11 \\
\hline Hypoxic brain damage & 1 \\
\hline Ischemic heart failure & 1 \\
\hline
\end{tabular}

NSTEMI, non-ST-segment elevation myocardial infarction; STEMI, ST-segment elevation myocardial infarction; AV, atrioventricular. 


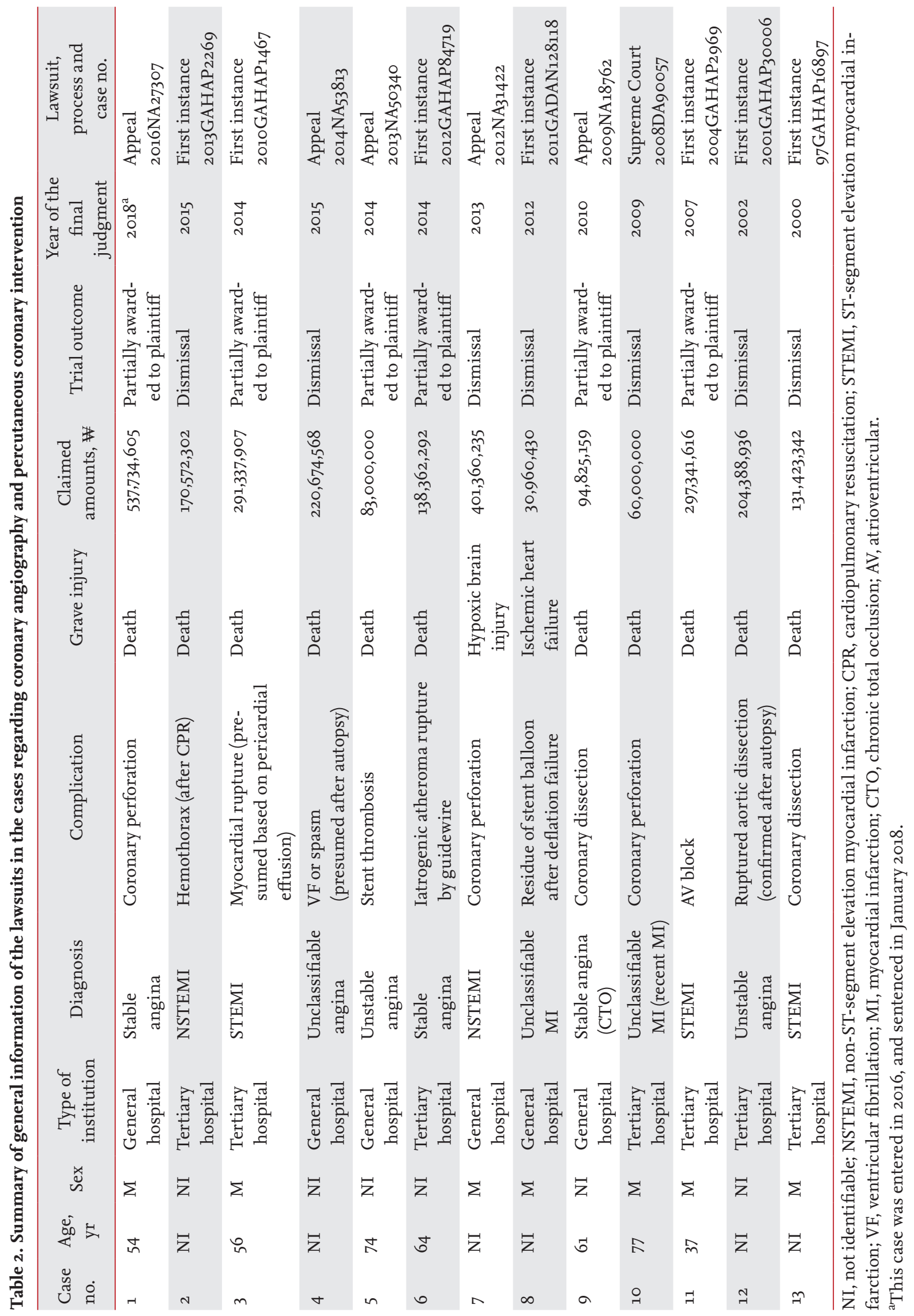



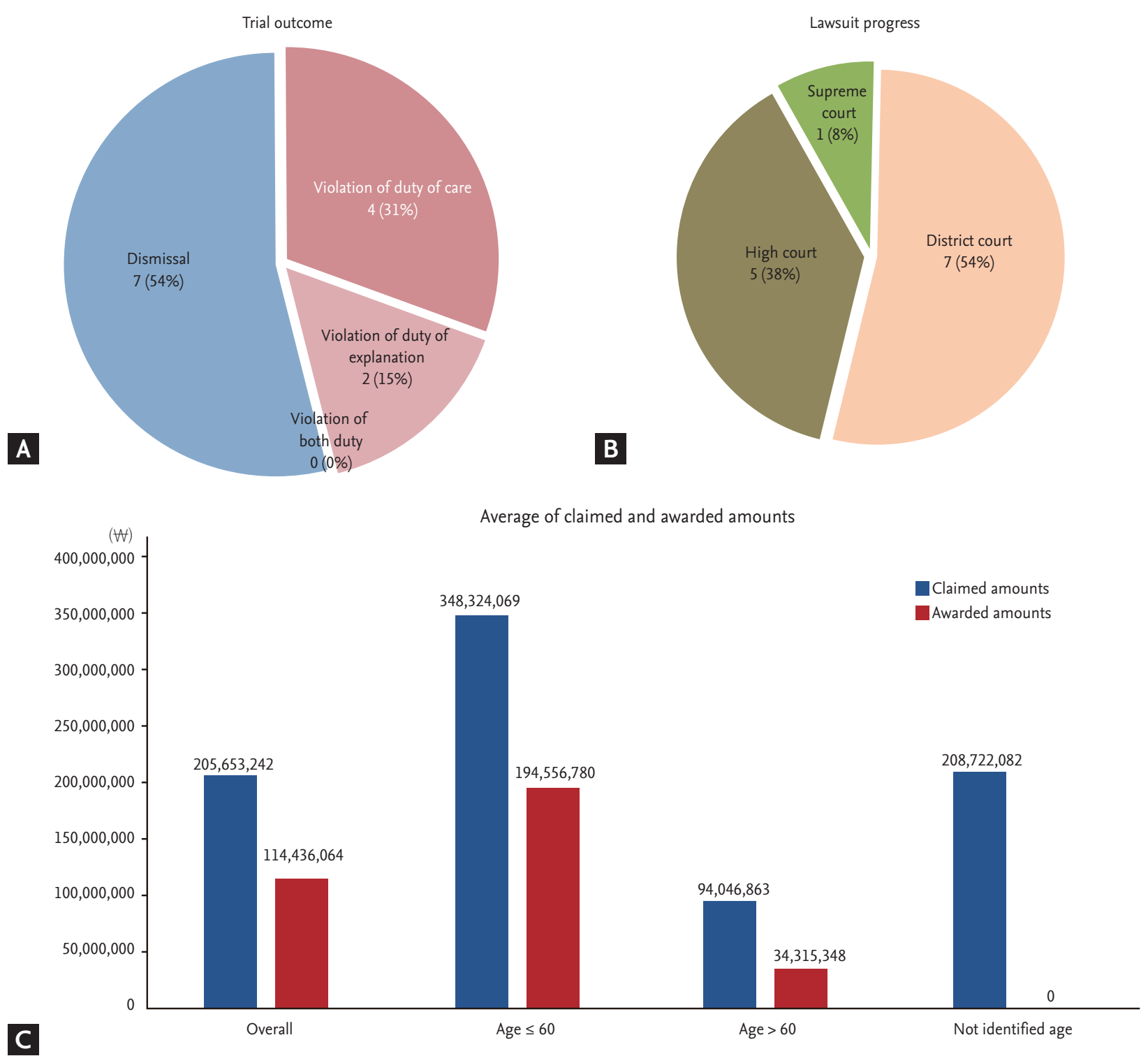

Figure 1. Judgment status. (A) Trial outcome. (B) Lawsuit progress. (C) Average of claimed and awarded amounts.

No cases were recognized as a violation of both duties. Of the total 13 cases, seven (54\%) were sentenced in the first instance, five (38\%) during the appeal, and one (8\%) in the Supreme Court (Fig. 1B). The average claimed amount was 205,653,242 KRW and the average awarded amount was 114,436,064 KRW (Fig. 1C). The awarded amount comprised lost earning capacity, funeral expenses, treatment expenses, consolation money, and limitation of liability. Details of the awarded amounts are shown in Table 3.

\section{Violation of duty of care}

Four cases were ruled in favor of the plaintiff (from 13 total cases that claimed violation of duty of care) (Table 4). Of them, three were ruled as performance error and one as diagnostic error around the course of PCI.

As can be seen in Table 2, the cases were titled according to their date. In case no. 1, there was a no-reflow phenomenon after stent deposition, and repetitive balloon dilatation was performed on the lesion of the coronary artery. Thereafter, coronary perforation occurred. Negligence was recognized because of perforation from re- 


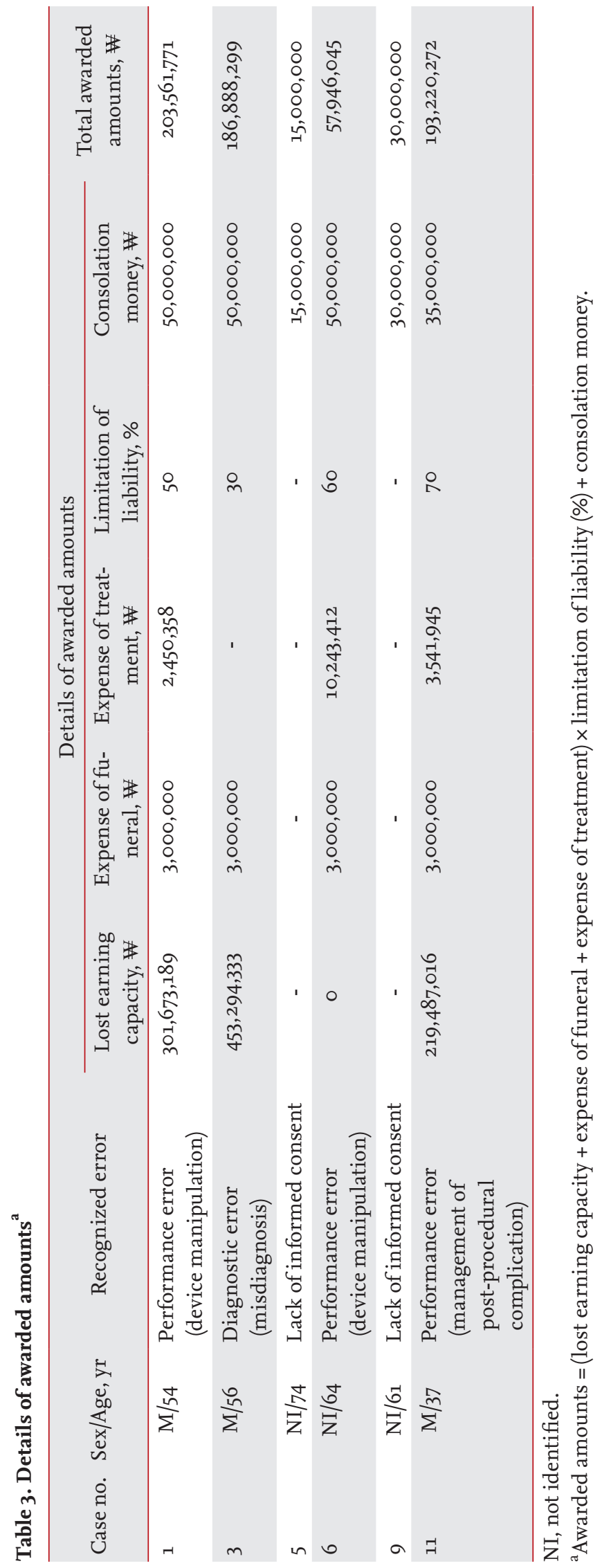

peated balloon dilatation without identification of the cause of the no-reflow phenomenon, despite no highrisk lesions, such as calcified or tortuous lesions, having been observed.

In case no. 3, revascularization, such as thrombolysis or PCI, was delayed for seven hours because of a misdiagnosis of acute MI based on the presence of $\mathrm{Q}$ wave on the electrocardiogram (ECG), leading to a diagnosis of recent MI. The court recognized the misdiagnosis based on the existence of ST-segment elevation on the ECG and the cardiac marker, with initial normal range, becoming elevated in a matter of hours. Therefore, the court determined that there had been negligence by the physician because there was a causal relationship between misdiagnosis, delays in revascularization, and death.

In case no. 6, negligence of inappropriate device manipulation was identified because of acute thrombotic occlusion caused by iatrogenic atheroma rupture with a device such as a guidewire or intravascular ultrasound (IVUS) catheter. Delayed revascularization by two episodes of guidewire distortions and guidewire also repeatedly stimulated myocardium and induced ventricular fibrillation.

In case no. 11, Adams-Stokes syndrome (characterized by a decrease in cardiac output and loss of consciousness due to a transient arrhythmia such as AV block or tachy-brady syndrome [9]) occurred from decreased cerebral blood flow after AV block-induced bradycardia, resulting in cerebral infarction. The court ruled that although death itself is highly likely due to MI and cardiogenic shock, there was a causal relationship between cerebral infarction, the fact that a temporary pacemaker should have been inserted, and, possibly, death. In the end, physician negligence was determined.

On the other contrary, nine cases with a total of 28 issues related to violation of duty of care were dismissed (Table 5). Errors in management after complications and procedural skills were alleged by the plaintiffs in most of the dismissed cases.

The court pointed out that the plaintiff must prove the physician's fault, such as by exhibiting a substandard level of medical knowledge or skill or any violation of fiduciary duty. Thus, evidence should be presented to prove the physicians' fault, but in most dismissed cases, there was insufficient or no evidence of malpractice. For 
Table 4. Plaintiff claims and reasons for indemnity in cases of violation of duty of care

\begin{tabular}{|c|c|c|c|c|}
\hline Case no. & $\begin{array}{l}\text { Final trial } \\
\text { court }\end{array}$ & Fault & Plaintiff claims & Reasons for indemnity \\
\hline 1 & Appeal & $\begin{array}{l}\text { Performance } \\
\text { error }\end{array}$ & $\begin{array}{l}\text { Fault of coronary perforation by } \\
\text { error of device manipulation }\end{array}$ & $\begin{array}{l}\text { No vulnerable precursor lesion of coronary perfo- } \\
\text { ration like severely calcified or tortuous lesion } \\
\text { Repetitive stent balloon dilatation without identifi- } \\
\text { cation of the cause of no-reflow phenomenon after } \\
\text { stent deposition }\end{array}$ \\
\hline 3 & $\begin{array}{l}\text { First in- } \\
\text { stance }\end{array}$ & $\begin{array}{l}\text { Diagnostic } \\
\text { error }\end{array}$ & $\begin{array}{l}\text { Misdiagnosis as recent MI rath- } \\
\text { er than acute MI based both on } \\
\text { chest pain } 1 \text { week ago and pres- } \\
\text { ence of Q wave on ECG } \\
\text { Delayed reperfusion therapy such } \\
\text { as thrombolysis or PCI at } 7 \text { hours } \\
\text { after arrival at ER }\end{array}$ & $\begin{array}{l}\text { Recognized misdiagnosis based on both the pres- } \\
\text { ence of S-T segment elevation on lead } V_{1}-V_{4} \text { and } \\
\text { steep elevation of follow-up cardiac marker from } \\
\text { initial normal range } \\
\text { Delayed reperfusion therapy led to death }\end{array}$ \\
\hline 6 & $\begin{array}{l}\text { First in- } \\
\text { stance }\end{array}$ & $\begin{array}{l}\text { Performance } \\
\text { error }\end{array}$ & $\begin{array}{l}\text { Fault of management failure and } \\
\text { induction of ventricular fibrilla- } \\
\text { tion with error of device manipu- } \\
\text { lation }\end{array}$ & $\begin{array}{l}\text { Recognized negligence of device manipulation be- } \\
\text { cause of acute thrombotic occlusion by iatrogenic } \\
\text { atheroma rupture with device such as guidewire } \\
\text { or IVUS catheter } \\
\text { Delayed revascularization by two episodes of } \\
\text { guidewire distortion } \\
\text { Induced ventricular fibrillation and death by re- } \\
\text { petitive stimulus of guidewire }\end{array}$ \\
\hline 11 & $\begin{array}{l}\text { First in- } \\
\text { stance }\end{array}$ & $\begin{array}{l}\text { Performance } \\
\text { error }\end{array}$ & $\begin{array}{l}\text { No temporary pacemaker on AV } \\
\text { block resulted in aggravation of } \\
\text { Adams-Stokes syndrome and } \\
\text { cerebral infarction }\end{array}$ & $\begin{array}{l}\text { Temporary pacemaker should have been inserted } \\
\text { to manage AV block with decreased cerebral per- } \\
\text { fusion }\end{array}$ \\
\hline
\end{tabular}

MI, myocardial infarction; ECG, electrocardiogram; PCI, percutaneous coronary intervention; ER, emergency room; IVUS, intravascular ultrasound; $\mathrm{AV}$, atrioventricular.

Table 5. Disputed claims of the plaintiffs in nine dismissed cases

\begin{tabular}{lc}
\hline Variable & Number \\
\hline Errors in management after complication & 8 \\
Errors in procedural skills & 7 \\
Errors in decision of therapeutic strategy & 5 \\
$\begin{array}{l}\text { Failure to recognize complication } \\
\text { after procedure }\end{array}$ & 2 \\
Fabricated evidence submitted & 2 \\
No prescribed antiplatelet agents & 2 \\
Errors in diagnosis & 1 \\
Errors in checking for defects of devices & 1 \\
\hline
\end{tabular}

example, in a case in which the patient presented with sudden death three days after PCI, and aortic dissection rupture was confirmed after an autopsy, the plaintiff al- leged the following: (1) aortic dissection may be misdiagnosed as unstable angina based on chest pain prior to the procedure and (2) aortic injury had occurred during the procedure based on the patient's severe back pain after PCI. The court judged that the diagnosis of unstable angina was not a deviation from standard care, based on the stenosis of vessels on the CAG and the improved symptoms after PCI. There were no findings indicating aortic dissection, such as mediastinal widening around the procedure. In addition, the court recognized that severe back pain, not a specific symptom for suspecting aortic dissection, may occur due to supine position on bed required to prevent bleeding after the procedure. Therefore, the possibility of aortic dissection around the PCI was not proven due to lack of evidence.

Claims based on nonspecific symptoms alone or other diseases showing lack of probability were dismissed. In a case with stent thrombosis, the plaintiff claimed 
that there was delayed recognition of the complication despite the complaint of nonspecific chest discomfort. However, the court dismissed the claim because nonspecific chest discomfort frequently occurs after a PCI. In addition, as there were no signs of MI on the ECG, it was judged that a CAG was not urgent. In a case with hemothorax confirmed after cardiopulmonary resuscitation (CPR), the plaintiff claimed that the hemothorax was a procedure-related complication. However, the judge denied that there was a causal relationship, as hemothorax is not a common complication, and hypovolemic shock should have occurred immediately if the aorta had been injured during the procedure. Furthermore, the patient had no complaints until the next morning. In addition, the court commented that a proximate causal relationship between the physician's negligence and the consequences, when there is a lack of probability, is not acceptable.

The court did not accept negligence only based on the fact that an adverse outcome had occurred. If complications occurred despite the physician's practice of medicine with a high standard of care, the court judged whether the given complication was outside of the generally accepted range based on the contents of the medical practice and procedures, the site and degree of the complication, the standard level of medical care at that time, and the proficiency of the physician in charge. In contrast to a previous case of coronary perforation in which the plaintiff was partially awarded, the court dismissed the plaintiff's claim that perforation occurred due to procedural error ruling that negligence is not recognized by that fact alone in two other cases of coronary perforation. In one of the two case, the court dismissed the plaintiff's claim that the unreasonably expanded balloon led to the coronary artery perforation because contrast leakage was detected at the end of procedure, not immediately after the balloon dilatation. In the other case, the court recognized that there was no definitive evidence (such as the size, length, or pressure of the balloon, or inflation time, etc.) that the physician had violated the standard of care. In a case of stent thrombosis, the plaintiff claimed that it originated from the possibility of stent underexpansion. However, the court recognized that stent thrombosis is an unavoidable complication (with less than a $1 \%$ probability), and there is no way to expand the stent completely to contact the entire vessel area in the current level of medical care. The reasons provided were the size discrepancy of the proximal and distal reference vessels and the possibility of coronary dissection occurring when the balloon is inflated using higher pressure. Finally, the judge did not accept the allegation that disputed complications are beyond the range of general acceptance. In a case of deflation failure and residue of balloon in the vessel, the court dismissed the claim ruling that defects in the balloon itself could not be ruled out, and that there was no proof of the physician's malpractice. Additionally, in both dismissed cases of coronary dissection, negligence was not determined based on lack of evidence during the physicians' procedures.

\section{Violation of duty of explanation}

In nine of 13 cases, the plaintiffs insisted that the physicians had breached their duty of explanation. Two of those cases were admitted. In both cases, violations were recognized for the following reasons (Table 6).

In case no. 5, there was a manual description that emphasized the necessity of the procedure, but no information on the possibility of adverse outcomes. In case no. 9, a specified description about coronary dissection was not given, and only the unspecified vascular complications were mentioned. Additionally, the fact that it was a non-emergency situation was pointed out to support the infringement of right to self-determination through lack of explanation. For reference, the consent form being signed on the day before the procedure was highlighted to support the violation of duty of explanation in the first instance but not commented on in appeal.

The judgments noted that there was no additional explanation regarding details other than those printed in both cases. In general, to determine whether the situation was explained in detail, the court considered the presence of additional drawings such as circular marking or underlines on the printed contents, at least, as explanation.

In contrast, the other seven cases were dismissed for the following reasons. In four cases, from the evidence submitted, it was identified that sufficient informed consent was taken. In two cases, the plaintiffs claimed that the physician who explained the procedure was not the one who performed it. However, in both cases, the court ruled that the physician's performance itself was 
Table 6. Plaintiff claims and reasons for indemnity in cases of violation of duty of explanation

\begin{tabular}{|c|c|c|c|}
\hline Case no. & $\begin{array}{c}\text { Final trial } \\
\text { court }\end{array}$ & Plaintiff claim: lack of informed consent & Reasons for indemnity \\
\hline 5 & Appeal & $\begin{array}{l}\text { Insufficient explanation about the possibility } \\
\text { of death from procedural complication due to } \\
\text { myocardial infarction }\end{array}$ & $\begin{array}{l}\text { No signs of additional detailed explanation except } \\
\text { for the printed content about complications } \\
\text { Handwritten content emphasized only the neces- } \\
\text { sity of procedure, not the possibility of adverse } \\
\text { outcome }\end{array}$ \\
\hline 9 & Appeal & $\begin{array}{l}\text { No detailed explanation about the necessity and } \\
\text { risk of repeated procedure, especially the risk of } \\
\text { coronary dissection } \\
\text { Insufficient time to make decision because of } \\
\text { explanation about the procedural contents and } \\
\text { complications just one day before the procedure }\end{array}$ & $\begin{array}{l}\text { No signs of additional detailed explanation ex- } \\
\text { cept for printed content with difficult medical } \\
\text { terms-recognized as insufficient explanation } \\
\text { regarding the necessity for the procedure } \\
\text { No specific mention about coronary dissection- } \\
\text { just the mention of unspecified complications } \\
\text { regarding vessels-recognized as insufficient ex- } \\
\text { planation about the possible complications of the } \\
\text { procedure } \\
\text { Insufficient time given to make decision-the } \\
\text { consent form written just one day before the pro- } \\
\text { cedure (pointed out in the first instance) despite } \\
\text { it being a non-emergency procedure-supports } \\
\text { the infringement of self-determination }\end{array}$ \\
\hline
\end{tabular}

not negligent.

Lack of detailed explanations about unexpected critical consequences was claimed in one case, but it was dismissed because the scope of duty of explanation does not include explanations that are irrelevant to the procedure. As an example in case no. 2, the court recognized that the hemothorax that occurred after CPR was an irrelevant complication of the procedure considering the circumstances surrounding medical practice.

Regarding the signing of the agreement, in one case, the plaintiff claimed that the wife had signed on the agreement, not the patient himself, and that was a breach of duty. However, the court dismissed this claim recognizing the circumstances wherein explanation was given to both the patient and his wife.

In another case, the plaintiff claimed that there was no explanation regarding the capacity of the healthcare provider and the entire system to cope with an emergency if it did occur. The court ruled that an emergency could occur in any procedure, and in that case, the patient could be transported to a tertiary hospital, as a simple matter of common sense. In a situation wherein the plaintiff did not request further explanations about emergency handling, the court ruled that the extent of a physician's explanation does not include a guarantee for the choice of selecting other hospitals by preemptive self-notification.

\section{DISCUSSION}

In this study, the authors analyzed lawsuit judgments related to CAG and PCI over the past 20 years to present the status of disputes and the reasons for indemnity, and, in conclusion, to determine ways to prevent unnecessary disputes and medical malpractice suits.

\section{Estimation of awarded amount for damage}

There are substantial differences in the awarded amounts around the age of 60 because the court estimates the loss of daily income from the time of death to the age when an income can still be maintained, and the court generally recognize the age 60 as limit for earning capacity. There is no definite legal evidence that 60 is the age limit. However, the full court of the Supreme Court made such a judgment in December 1989, it has been upheld by several other Supreme Court decisions since then [10]. 
The limit of liability was set at $30 \%$ to $70 \%$, at the discretion of the court, reflecting the necessity of the procedure, patient factors, such as age, habits like smoking or drinking, high mortality rate of the disease, and whether other treatments except for negligence were performed well. Specific criteria for numerical determination remain unclear; however, the discretion of the court seems to be dominant, considering that the purpose of civil litigation is arbitration. The sum of the estimated lost earning capacity, expenses for the funeral, and treatment are then estimated based on the limit of liability. When consolation money is added to the above sums, it gives the total awarded amount. In cases of violation of duty of explanation, the awarded amount was judged to include only the consolation money, because violation of duty of explanation is not the same as violation of duty of care, as it does not have a causal relationship with adverse patient outcomes. The standard consolation money was set as $80,000,000 \mathrm{KRW}$ in 2008 , and it is still the current referenced standard. Final consolation money is judged at the discretion of the court in consideration of circumstances such as negligence and other factors. Usually, consolation money does not exceed 30,000,000 KRW when there is only violation of duty of explanation, even in exceptional cases [11].

However, amounts awarded in damages may increase as there are arguments saying that it is unreasonable to define 60 years as the limit of earning capacity, especially in the era of an aging society. In accordance with this trend, judgments using 65 years as the limit are increasing [12]. In addition, the basic consolation money is likely to be increased. Since the levels were set 10 years ago, there are also some arguments that the standard is too old and needs to be revised.

\section{Who should prove negligence?}

Currently, the side that has the responsibility to prove negligence of a physician in malpractice suits is the plaintiff. However, it is difficult to prove a scientifically clear causal relationship in civil litigation. Therefore, the court allow the plaintiff to prove a fact that there was malpractice in the process of medical practice based on matters of common sense, and an indirect fact that no other factors except malpractice were responsible for the adverse outcome, in other words, the patient did not have such medical history that can cause the outcome.
In this way, the court may recognize negligence of the physician, presuming the causal relationship between the medical practice and the adverse outcome, unless the physician proves that the outcome was resulted from an entirely different cause [13]. For instance, in case no. 1, causal relationship was admitted, demonstrating that there was no high-risk lesion such as a tortuous or calcified lesion.

However, in the case of proving negligence through such an indirect fact, the likelihood that any adverse outcome could be caused by medical malpractice should be assumed. It is not allowed to require the physician to prove non-negligence if there is only a presumption of a vague causal relationship [14].

Regarding violation of duty of explanation, the plaintiff is also responsible for proving negligence in principle. However, lack of explanation can be difficult to prove from the patient side, while physicians can document and demonstrate fulfillment of duty of explanation. Thus, the court has consistent precedents that the physician should prove there has been no negligence in duty of explanation [13].

\section{Violation of duty of care}

In an occupation that involves managing the life, body, and health of people, a physician has the duty of care to the best to prevent the risk of specific symptoms or circumstances for a patient when performing medical practices such as physical examinations and treatment. Duty of care involves foreseeing adverse outcomes as well preventing those adverse outcomes. Criteria for determining medical malpractice are generally based on the standard level of medical care generally practiced in current clinical medicine [13].

Regarding the duty to foresee adverse outcomes, foreseeability is judged by clinically proven and published evidence, and it is sufficient if there is a possibility that the occurrence of the risk depends on the given circumstances [15]. The case no. 3 may correspond to this situation. In spite of the elevation of ST segment, the physician failed to recognize urgency based on the presence of $Q$ wave on ECG, misdiagnosed as prior infarction. In general, $\mathrm{Q}$ wave reflects damaged myocardium including a prior infarction. However, it may also reflect the delayed treatment of current infarction, which cannot rule out the acute myocardial infarction. Therefore, 
through accurate reading of ECG, physicians should not make a mistake and miss the appropriate time point for a myocardial infarction treatment [16].

However, no obligation can be imposed on a physician if there are no foreseeability of the adverse situations [15]. In each case of ruptured aortic dissection confirmed after autopsy and hemothorax confirmed after CPR, the claims of mistreatment were dismissed because there were no objective or suspicious clinical findings of the disease such as a specific symptom or laboratory or radiologic evidence.

As for duty to avoid adverse outcomes, physicians have an obligation to avoid foreseen risks. However, violation of such duty was notable in the case no. 11. After PCI, the patient had neurologic symptoms due to persistent bradycardia from AV block, but the physician did not insert a pacemaker and cerebral infarction occurred. If bradycardia, such as an AV block, is accompanied by hypotension or an altered mental status, atropine is the first agent [17]. However, it is ineffective against an infra-Hisian block [18], when other chronotropic agents such as dopamine or epinephrine may be helpful. Transcutaneous or transvenous pacing, such as with the use of a temporary pacemaker, should be considered if medications are not effective [17]. In the case, the judgment was determined that not inserting a pacemaker against the symptomatic AV block was negligent, of which actions to increase the heart rate were recognized as below the standard level.

In addition, there was a case with recognized negligence in the process of dealing with the no-reflow phenomenon. Generally, the cause of a no-reflow phenomenon is likely multifactorial due to a combination of endothelial damage, platelet and fibrin embolization, vasospasm, and extracellular or intracellular tissue edema, ultimately leading to neutrophil plugs and platelet infiltration of myocardial tissue and microcirculation injuries [19]. At first, very selective and distal intracoronary or intravenous vasodilator such as adenosine [20,21], nicorandil [22], nitroprusside, nicardipine, or verapamil $[23,24]$ is tried. Otherwise, epinephrine may be helpful $[25,26]$. If the problem is associated with the thrombus, intravenous or intracoronary abciximab or thrombus aspiration may be helpful $[27,28]$. Nevertheless, if the acute closure continues, the exact underlying pathology should be determined using intravascular imaging [19].
However, the physician did not try to assess the cause of no-reflow phenomenon, but repeated ballooning, which resulted in coronary perforation and was recognized as negligence.

It is noteworthy that even if a risky situation could be made inevitably, it was recognized as negligence if repeated. In the case no. 6 , the iatrogenic plaque rupture caused by guidewire or IVUS catheter and the additional delayed revascularization by repetitive guidewire distortions were recognized as negligence by the physician due to repetitive failure in device manipulation.

All medical practices imply some degree of risk. In some cases, the patient cannot avoid treatment, and so must take the risk. Therefore, a physician cannot always assume responsibility for an adverse outcome. In the previous dismissed cases, we have confirmed that negligence was not determined based merely on the fact that adverse outcomes occurred; there was absence of objective evidence that the physician made a mistake or violated duty of care.

In conclusion, physicians do not need to excessively perform defensive medicine by reacting too sensitively to unavoidable situations that are objectively unpredictable and uncontrollable. Because the judgments consistently showed that the court system had looked at the probability, the foreseeability, and the evidence. According to the judicial content of one of the past judgements cited in this study, negligence of the physician is not unconditionally recognized unless it goes beyond the reasonable range. Since the court has ruled whether the physician violated the standard of care based on the advice of medical associations or of a specialist at a tertiary hospital, physicians need not fear an unfair judgment so long as they follow the standard of care. Therefore, ECGs should be read carefully so that a necessary urgent revascularization is not delayed. Also, regarding the procedure, physicians should maintain reasonability in the choice of inflation balloon or stent regarding its size, length, inflation time, and pressure. Considering that a potential complication may progress to become critical within a short time, physicians should react promptly to any early signal of complication. In addition, it is essential for physicians to have in-depth knowledge of the various potential complications related to the procedure and be prepared to react in a structured approach [19]. 


\section{Violation of duty of explanation}

Probable sequelae or side effects related to the scheduled procedures should be the object of explanation if it typically occurs related to the procedure or if it results in irreversible and critical damage. Duty of explanation cannot be exempted by the fact that the likelihood of such side effects occurring is rare. If a patient has not been given detailed information about the possible outcomes, including the possibility of death, the physician has failed to fulfill his duty of explanation [29]. However, the contents of explanation should include relevant details focusing on the probable side effects of the invasive procedure, not around any medical processes. The contents to be explained have been stipulated in medical law since 2017, as follows [30]:

1. Diagnosis of the symptom which has occurred to or which might occur to the patient

2. Necessity, methods, and details of the surgery, etc.

3. The name of the physician, dentist or oriental medical doctor who gives explanation to the patient, or the name of principal physician, dentist or oriental medical doctor who participates in the surgery, etc.

4. Sequelae or side effects expected to occur typically following the surgery, etc.

5. Matters to be observed by the patient before and after the surgery, etc.

It has been pointed out several times that complications that can lead to fatal outcomes are not sufficiently explained. Providing only a simple listing or printed contents with difficult medical terms does not cover the duty of explanation. Therefore, each specified complication should be explained in an understandable way with proper additional handwritten drawings (at least including circular markings or underlined material) on the printed contents.

In the case of an emergency, an exemption from duty of explanation is generally recognized [29]. In this paper, there were three cases of STEMI. In two of the three STEMI cases, a violation of the duty of explanation was not even claimed. In the one exceptional case that did claim an insufficient explanation about PCI in the STEMI patient, PCI had been planned after thrombolysis, not as an emergency. For reference, in a case where the infringement of the right to self-determination was already recognized due to the insufficient explanation about the necessity for and the possible complications of the procedure despite being a non-emergency, there was commentary about the time that informed consent was received and whether the patient had enough time to consider the procedure.

Regarding the person in charge of the explanation, it is also possible that explanations could be given by a physician not assigned to the patient, unless there are special circumstances [29]. Accordingly, claims of negligence regarding the explanation provided by another physician who did not participate in the procedure were dismissed as above. However, the names of the physician who explains and the one who participates in the procedure should be clarified in the informed consent in accordance with the Medical Service Act [30]. It should be noted that medical assistants (such as nursing assistants or hospital clerks) who are not physicians are not allowed to perform physicians' duty of explanation in the place of physicians [29].

A dispute could possibly be caused if the signature of informed consent is not made by the patient him/herself. In the enforcement ordinance of Medical Service Act, legal representatives can receive consent only when the patient lacks decision-making ability [30]. Therefore, physicians should explain the situation to the patient directly and the signature of informed consent should be given by the patient himself. If that is not possible, the reasons should be clarified.

In conclusion, given the lack of understanding of the potential for complications, patients and caregivers are not ready to accept possible complications, and that can lead to disputes. Thus, it is also necessary for physicians to provide enough information so patients and caregivers have a thorough understanding of the difficulty of avoiding the inevitable risk of adverse outcomes.

\section{Limitations of this study}

This study is based only on the contents of lawsuits in which rulings were handed down. Thus, some of the patients' clinical information was missing. Lack of access to patients' medical records is another limitation. It should also be noted that the determination of negligence in the cases herein came from the judge's perspective, not that of a professional physician. In addition, disputes can be resolved in other ways, like arbitration, not solely by litigation. Considering the relatively low incidence of critical adverse outcomes, the number of 
disputed cases may be insufficient. Thus, the 13 cases we have found may not accurately reflect the entirety of such disputes. However, this paper is meaningful in that it is the first to systematically analyze disputes related to CAG and PCI based on lawsuit judgments in Korea. There has been no previous research on the specific topic of CAG/PCI lawsuits and analysis of specific reasons for court decisions. Finally, we hope that analysis of previous experiences will have an effect in reducing unnecessary and medical malpractice suits.

\section{KEY MESSAGE}

1. The incidence of medical disputes and the award amounts for damage related to coronary angiography/percutaneous coronary intervention may increase.

2. To reduce medical malpractice and disputes, caution with foresight, early recognition, and management of complications regarding standard of care are vital.

3. Specific, detailed, and comprehensible explanations, including the risk of complications, are also important.

\section{Conflict of interest}

No potential conflict of interest relevant to this article was reported.

\section{REFERENCES}

1. Hwang MS. The Legal Scheme for Resolving Conflicts between Patients and Physicians. Seoul (KR): Seong Min Press, 2005.

2. Korea Medical Dispute Mediation and Arbitration Agency. Statistical yearbook 2017 [Internet]. Seoul (KR): Korea Medical Dispute Mediation and Arbitration Agency, c2017 [cited 2019 May 25]. Available from: https://www.k-medi. or.kr/lay1/bbs/S1T27C96/A/25/list.do.

3. World Health Organization. The top 10 causes of death [Internet]. Geneva (CH): World Health Organization, c2019 [cited 2019 May 25]. Available from: http://www.who. int/news-room/fact-sheets/detail/the-top-10-causes-ofdeath.
4. Sanchis-Gomar F, Perez-Quilis C, Leischik R, Lucia A. Epidemiology of coronary heart disease and acute coronary syndrome. Ann Transl Med 2016;4:256.

5. Hata J, Kiyohara Y. Epidemiology of stroke and coronary artery disease in Asia. Circ J 2013;77:1923-1932.

6. Kandan SR, Johnson TW. Management of percutaneous coronary intervention complications. Heart 2019;105:7586.

7. Han S, Park GM, Kim YG, et al. Trends, characteristics, and clinical outcomes of patients undergoing percutaneous coronary intervention in Korea between 2011 and 2015. Korean Circ J 2018;48:310-321.

8. Shin S, Jang SG, Min K, Lee W, Kim SY. The legal doctrine on the liability of physicians in medical malpractice lawsuits involving complex regional pain syndrome. J Korean Med Sci 2018;33:e46.

9. Harbison J, Newton JL, Seifer C, Kenny RA. Stokes Adams attacks and cardiovascular syncope. Lancet 2002;359:158160.

10. Choi BK. A study on the working period of the old people for compensation. J Claim Adjust 2017;15:5-38.

11. Kim KR, Ahn BY. Assessment of damages for non-pecuniary loss and compensation for damages in medical accidents: overview for cases of medical injury relief in Korea consumer agency. Korean J Law Med 2012;13:179214 .

12. Kim DS. “The limitation of manual workers' earning capacity, the age of 65 " was admitted again [Internet]. Seoul (KR): Legal Times, c2019 [cited 2019 May 25]. Available from: http://www.legaltimes.co.kr/news/articleView. html?idxno=40604.

13. You H. Civil liability for medical malpractice. J Korean Med Assoc 2013;56:648-654.

14. Kim SY, Seo MH, Shin SC, et al. Medical case law analysis. J Korean Academy Adv Gen Dent 2014;3:9-13.

15. Jun $\mathrm{HH}$. The legal meaning of the endoscopic guideline. Korean J Gastrointest Endosc 2004;29:161-174.

16. Mercuri M, Natarajan MK, Velianou JL. ST-elevation myocardial infarction: is there time for $\mathrm{Q}$ waves? CMAJ 2012;184:1125-1126.

17. Neumar RW, Otto CW, Link MS, et al. Part 8: adult advanced cardiovascular life support: 2010 American Heart Association Guidelines for cardiopulmonary resuscitation and emergency cardiovascular care. Circulation 2010;122:S729-S767.

18. Kantharia BK, Shah AN. Nodal and infranodal atrioven- 
tricular conduction block: electrophysiological basis to correlate the ECG findings. Indian Heart J 2013;65:229231.

19. Giannini F, Candilio L, Mitomo S, et al. A practical approach to the management of complications during percutaneous coronary intervention. JACC Cardiovasc Interv 2018;11:1797-1810.

20. Micari A, Belcik TA, Balcells EA, et al. Improvement in microvascular reflow and reduction of infarct size with adenosine in patients undergoing primary coronary stenting. Am J Cardiol 2005;96:1410-1415.

21. Kunadian V, Zorkun C, Williams SP, et al. Intracoronary pharmacotherapy in the management of coronary microvascular dysfunction. J Thromb Thrombolysis 2008;26:234-242.

22. Ito $\mathrm{H}$, Taniyama $\mathrm{Y}$, Iwakura $\mathrm{K}$, et al. Intravenous nicorandil can preserve microvascular integrity and myocardial viability in patients with reperfused anterior wall myocardial infarction. J Am Coll Cardiol 1999;33:654-660.

23. Rezkalla SH, Dharmashankar KC, Abdalrahman IB, Kloner RA. No-reflow phenomenon following percutaneous coronary intervention for acute myocardial infarction: incidence, outcome, and effect of pharmacologic therapy. J Interv Cardiol 2010;23:429-436.

24. Su Q, Li L, Liu Y. Short-term effect of verapamil on coronary no-reflow associated with percutaneous coronary intervention in patients with acute coronary syndrome: a systematic review and meta-analysis of randomized controlled trials. Clin Cardiol 2013;36:E11-E16.

25. Aksu T, Guler TE, Colak A, et al. Intracoronary epinephrine in the treatment of refractory no-reflow after primary percutaneous coronary intervention: a retrospective study. BMC Cardiovasc Disord 2015;15:10.

26. Skelding KA, Goldstein JA, Mehta L, Pica MC, O’Neill WW. Resolution of refractory no-reflow with intracoronary epinephrine. Catheter Cardiovasc Interv 2002;57:305309 .

27. Stone GW, Maehara A, Witzenbichler B, et al. Intracoronary abciximab and aspiration thrombectomy in patients with large anterior myocardial infarction: the INFUSE-AMI randomized trial. JAMA 2012;307:1817-1826.

28. Svilaas T, Vlaar PJ, van der Horst IC, et al. Thrombus aspiration during primary percutaneous coronary intervention. N Engl J Med 2008;358:557-567.

29. Korea Ministry of Government Legislation. Easy to find, practical law: medical disputes [Internet]. Sejong (KR): Korea Ministry of Government Legislation, c2019 [cited 2019 May 25]. Available from: http://www.easylaw.go.kr/ CSP/CsmMain.laf?csmSeq=567.

30. Korea Legislation Research Institute. Medical service act article 24-2 (Explanation about medical practices) [Internet]. Sejong (KR): Korea Legislation Research Institute, c2017 [cited 2019 May 25]. Available from: https://elaw.klri. re.kr/kor_service/lawView.do?hseq=40970\&lang=ENG. 